\title{
The Photograph Collection and its Problems
}

Miss Mitchell is assisting in the organization of the Biblioteca del Estado de Jalisco at Guadalajara, Mexico. This paper was presented January 29, I94I, at a meeting of the College Art Association held at the University of Chicago.

\section{Need for a Broad Viewpoint}

$\mathrm{T}$ HE ACQUISITION, care, and arrangement of the photograph and slide collection has developed into a formidable science, demanding of its administering custodian enduring patience, long-range perspective, and clear thinking. Too often photograph curators become so engulfed in detail that they lose sight of their true function in the educational scheme of their college or university art departments or in their museum. With them rests the responsibility of making readily available to faculty, students, curators, and laymen a collection of visual material of widely diversified subject matter. An objective approach and the use of the simplest procedures of custodianship should be a constant goal.

In the past, interest has been directed toward the acquisition and care of the photograph and slide collection, problems which have been well summarized by the late Elizabeth M. Fisher of the Ryerson Art Library of the Chicago Art Institute in her excellent discussion of "The Fine Arts Picture Collection" in the Library
Journal for October 15, 1939. Less attention has been given to the formulation of a code for curators. The following remarks, based on a survey of fourteen representative photograph collections in colleges, universities, and museums, suggest the bewildering number of methods in use in our institutions. A careful study of these variations emphasizes the desirability of further comparison and analysis leading toward the publication of a handbook which might be useful in the organization of the photograph collection.

There is a tendency among guardians of these collections to consider the material in their charge overprecious. Rules should be made sparingly with service ever kept in mind. For example, college and university departments might consider a broader loan policy of photographic material. In some institutions photographs not on reserve for specific courses are loaned to students for a period of a week, with a fine of one cent a day for late return. Would it not be well to risk occasional damage to photographs, if in doing so, material were made more accessible to interested students? Although newly-acquired photographs are invariably brought to the attention of the professor or staff member concerned with the subject, others may be given an idea of the expanding collection by frequently-changed exhibits of current additions. 


\section{Housing the Collection}

Of the fourteen institutions under consideration all but three house their extensive photograph collections in vertical files. The two types in use are files of drawers and, more frequently, cabinets made up of many compartments with a drop front for each tier. It is surprising that more institutions have not resorted to the compartment file which requires the least physical exertion of any of the systems. This setup was illustrated by photograph and diagram as early as I9I I in the publication of the Metropolitan Museum of Art concerned with Classification Systems in Use in the Library. The three institutions which do not use vertical files, house their material in boxes, a method which is being adopted by the National Gallery of Art in Washington. The use of boxes seems to be more popular in large institutions where files are not open to the public and are likely to be farther from the study room. Here untrained attendants produce on request material called for by classification number or subject, in contrast to the trained curators or art-minded students in charge of the average college or university collection.

\section{The Card Catalog-Special Indexes}

The question of a card index to the collection should be decided only after considering the cost of preparation in time, labor, and materials in relation to the projected use to which such a catalog would be put. In the small college or university with a limited art enrolment and few or no graduate students, there is scarcely a need for a catalog of the collection. But in the larger university, with emphasis on graduate study or in the museum dealing with a varied public, a catalog is highly desirable and insures the tracing of every iconographic detail. Whether or not a catalog is planned every collection should have an authority file of place and personal names. Other special indexes may prove valuable in lieu of a catalog: an index of colored reproductions, an index of architects when architecture is filed under period or country and city, or an index of portraits where painting and sculpture are filed by artist. The presence of a catalog reduces in one sense the worries of the classifier. If a photograph of an object may logically be filed in any one of three places, the classifier may decide upon one and make subject cards for all three to prevent the photograph's being "lost" to the public. For example the reproduction of a jeweled book cover may be readily produced whether the inquirer is interested in metal-work, gems, or book arts.

\section{Classification}

Curators charged with the responsibility of the photograph collection with one accord pass by the minor issues raised by acquisition, accession, mounting, and housing, to the absorbing task of arrangement or classification. The libraries of our country are, for the most part, taken care of adequately by two systems of classification, the Dewey Decimal and the Library of Congress. A survey of the fourteen representative classification schemes for photograph collections is discouraging in that it reveals no standardization. While no two systems of notation are exactly alike, several are based on the original Metropolitan Museum of Art plan. Each new curator who comes along scans the existing systems, is confounded, extracts some features from one classification, some from another, and adds a new scheme which increases the confusion. It may be 
too late to bring order out of the present chaos, but perhaps something can be done to formulate a guide or code for those yet unborn collections.

Whether the curator is fond of the A.B.C.'s or "plays the numbers," that these are merely arbitrary symbols to designate classification and so are relatively unimportant in comparison to logical arrangement of material, must be remembered. Since all of these institutions, however, college, university, or museum, have photograph collections composed, on the whole, of the same type of subject matter, can it be the use to which the collection is put in these institutions that causes the variety in classification? The photograph and slide collection of the college and university art department is drawn upon to visualize the history of art course, varyingly concerned with subject, period, or country, such as the history of the portrait, medieval art, or French painting. Is the function of the museum collection so completely at variance with this concept? It must be able to supply the curator of sculpture with material for his scholarly report on the newly-acquired Gothic statue of the Virgin, the textile designer for inspiration in creating new fabrics, or the schoolteacher with a series of historic castles.

\section{Discrepancy in Classification}

Some of the discrepancy in classification notation has undoubtedly been brought about by professors and museum curators who, though scholars and specialists in their fields, are not library-detail-minded and are apt to think only in terms of their own courses or subjects, rather than of the photograph collection as a whole. Photograph curators have sometimes admitted that they arrange their material to suit the needs, or rather the wishes, of their faculty and staff, perhaps not giving due consideration to the fact that in five years another set of scholars with different fields of interest may be on hand to request a rearrangement of material. The intrusion of personal interests and prejudices is apparently hard to avoid but should be guarded against.

In this survey of classification schemes it has been observed that the favored plan is a primary division of the collection by subject, such as architecture, sculpture, painting, and the various minor arts. Under subject arrangement the general order is by period, country, and then alphabetically by city or artist. Museums tend to one or two period subdivisions, as do several colleges and universities. Some universities, however, have as many as five or more time or culture subdivisions. The two-period division is that most frequently encountered and to the librarian-curator, accustomed to classifying books by subject, is likely to suggest itself as a more simple and logical arrangement. Here the mental process is Ancient Architecture-Greek or Roman; Modern Architecture-English, French, or German. Modern is here thought of varyingly as the beginning of the Christian era or 600 A.D. On the other hand the curriculum-minded college or university curator may be far more period-conscious and insist on medieval French architecture as being more closely allied to English and German medieval architecture than to French architecture as a whole. In other words, he is less nationality bound, which may be perfectly consistent with the international nature of the medieval period, but it still makes difficult the classifying of a photograph of a building which is the work of medieval, renaissance, and modern craftsmen. 
New York University's System

New York University has departed from the usual division of material by subject in organizing its collection: first by large culture circles, such as ancient cultures of the Mediterranean (A); second, by smaller culture circles as, for example, Greece and Rome $(\mathrm{O})$; third, by medium (20000-sculpture); fourth, by country ( $100-G r e e c e) ; ~ f i f t h$, by style or historical time period (4-Hellenistic). The resulting call number would be $\mathrm{AO}$

20104.

Similarly :

$\begin{array}{lll}\text { BC } & \text { Europe } & \text { Medieval-Baroque } \\ 20405 & \text { Sculpture } & \text { Italy XV century } \\ 270 & \text { Donatello } & \end{array}$

Here the sixth subdivision (270) is a numerical symbol to indicate alphabetical arrangement according to artist. In other instances it might refer to place or iconography.

Opinions differ as to the necessity of planning the university photograph or slide classification around the courses conducted. Some institutions go so far as to have groups of photographs for each course filed separately. Since the same photograph may be used at different times during the year by different professors, a common file of material with a share-thewealth program would eliminate the necessity of duplicates. Lists of photographs used for a course could be kept from one year to another as a basic group for future study. Whether the emphasis of the classification is on subject, period, or style, the imaginative professor will draw upon material from varying groups of classification subdivisions. Any classification scheme becomes of necessity complicated. It is likely that professor or layman in using the collection must be inducted into the mysteries of local arrangement and can be trained to use one system as well as another, with preference always for any simplification possible. Two of the college and university systems studied having no catalogs, eliminate entirely any classification symbols although each follows a definite plan of filing according to subject and multiperiod division.

\section{Emphasize Alphabet and Number}

It has been indicated that some classifications emphasize the alphabetical symbol and some the number. Actually all but two of the schemes under consideration use a mixed notation, these two being entirely numerical. In the three institutions which use a letter as the first symbol, the letter does not, however, have the same signification. At New York University, as noted above, the letter indicates a culture circle. In the department of fine arts at the University of Pittsburgh, the photograph collection, which is adjacent to a library classified according to the Library of Congress scheme, uses corresponding symbols as far as L.C. goes and then employs other letters for additional subjects. The third institution in this category, the Ryerson Library, is the most consistent in its use of the alphabet for here $A$ stands for architecture, $B$ for biography, $C$ for customs and manners, etc. Here also, except in the ancient division, country is indicated by its first letter or letters as are further subdivisions.

The Cutter tables, so sacred to librarians in their arrangement of personal and place names, have at New York University not been used in order to avoid any possible confusion in filing photographs or slides of monuments located at one site but dating from different periods. In the letter and number combinations on the 
telephone dial, the library of the Museum of Modern Art has found a workable substitute for the Cutter tables.

\section{Problems in Classification}

To discuss here the innumerable problems which confront the classifier would be impossible, but a few which have suggested themselves in this study may be mentioned. It may be well to admit that in many instances there is no right or wrong answer.

Anonymous and Attributed Works. The filing of anonymous painting and sculpture has on occasion presented itself as a problem. Varyingly it may be found at the beginning or at the end of the whole subject, arranged according to century, school, or place. The Fogg Museum of Art system differs in that an anonymous Italian painting of the fifteenth century would be arbitrarily placed in the alphabetical arrangement of artists under the word Italy. The symbol here would be It I 5. At the University of Pittsburgh where painting and sculpture are separated into ancient, medieval, and renaissancemodern categories, anonymous works of the renaissance, if medieval in spirit, are apt to be classed under the medieval period.

In some collections, works of uncertain attribution, copies, school pieces, etc., are interfiled with the original works of an artist and are sometimes filed according to degree of attribution at the end of the group of authenticated works. In the case of questioned attributions where there are duplicate photographs or slides, some institutions file duplicates under the various attributions. Likewise with two photographs of a mural painting, one might be filed under the subject of mural painting, the other with the easel works of an artist under painting. In the case of architectural sculpture, one photograph might be placed with architecture, a duplicate with sculpture. Some curators may prefer all photographs of one specific object in one place in the file with cross references under other possible locations.

Drawings and Prints. Curators have apparently been disturbed as to the classifying of drawings and prints. Most frequently drawings are found as a subdivision of painting and occasionally prints are also classed here. Actually it seems quite logical to juxtapose these three forms of the artist's graphic expression, using some symbol to group together the works in any one medium. In more cases than not, prints are classed as a generic group which may be more practical in institutions where a course in the subject is given. Drawings are also in some schemes thought of as being in a class by themselves. Sometimes the division is called graphic arts and both drawings and prints are included.

Manuscripts. Manuscripts are for the most part thought of as belonging to that bewildering miscellanea known as the minor arts, but occasionally one finds them grouped under painting with some distinguishing symbol to place them apart. In institutions which have an extensive collection they may be treated as a distinct class. The classification of any movable object primarily according to place is the separation of material according to a variable factor which has no significance in the history of art. In theory, place control may not be a logical subdivision of media but it may be the most practical solution in certain cases. A report from one of the curators concerned with manuscripts at the Morgan Library, indicates that, although manuscripts may be thought of by country and century, arrangement 
by library may be simpler, inasmuch as school and century attribution in the medieval period is so uncertain. This system is reasonable in view of the fact that most sound and scholarly publications in discussing manuscripts invariably mention their location and number, many being known only by library number. Here is another case where the special index is important, in the event that no general card catalog exists.

Minor Arts. The problem of the minor arts is undoubtedly the most confusing of all to the curator. A summary of various current practices in the collections surveyed shows that with only one exception the primary division of the general class of minor arts is by medium, such as works in mineral, metal-work, wood, textiles, etc. The following tabulation indicates three possible divisions under medium, the first being that most frequently encountered :

I.

$\begin{array}{lll}\text { Metalwork } & \text { Metalwork } & \text { Metalwork } \\ \text { Italy } & \text { Italy } & \text { I6th century } \\ \text { Bronze } & \text { I6th century } & \text { Italy } \\ \text { I6th century } & \text { Bronze } & \text { Bronze }\end{array}$

Still another idea is presented at the University of Pittsburgh which divides the minor arts, considered as one whole class, into time and culture periods before any other subdivision. Here all ancient minor arts are together, as are all those of the medieval, renaissance-modern periods and Mohammedan and Oriental cultures.

These general subdivisions under the minor arts are difficult to decide upon. In a sense one system may work out as satisfactorily as another. Disregarding the intrusion of personal prejudice, the preferential arrangement may have been regulated by convenience. The further breaking-up of a class of material provides even more serious complications. For instance, if American pottery is classed together, is it the fact that the reproduced object is Rookwood ware, that it was made in the nineteenth century, that it is in the Chicago Art Institute collection, or that it is a plate rather than a bowl, which should take precedence? This is a subject which needs much consideration. In making public their classification schemes institutions should give much more complete information as to actual detailed practices.

\section{Theory of Arrangement}

It may be repeated that, whether we are thinking of the minor arts or the collection as a whole, it does not seem possible to say that one system of arrangement is right, another wrong. In a small collection of a few thousand photographs and slides the medievalist may be made happy by placing all medieval arts in one drawer, box, or group of compartments. The curator of so small a collection has comparatively few worries.

But when one thinks of a collection of twenty thousand photographs, sixty thousand, one hundred thousand, or more, ever expanding, then more discrimination, keener judgment in classification must be applied. The thought must be not the mere massing of groups of like material together, but the problem of extracting one photograph from one hundred thousand. How often does the professor or museum curator, whether specialist in medieval, Oriental, or modern fields, come to the collection with the idea of just any photograph of medieval architecture or minor arts, Oriental painting or modern industrial design? $\mathrm{He}$ is more apt to want a French Romanesque church and have Moissac in mind, or to think of an Italian, thirteenth-century crozier in the Uffizi. 
The orientalist is likely to be concerned with a Sung scroll in the Boston Museum of Fine Arts, and the man of today may want a streamlined refrigerator and know there is a good American one designed by Norman Bel Geddes.

That classification should be a tool and not an end in itself cannot be reiterated too often. Although consistency in the pattern of classification from the general to the specific is desirable, success of the scheme should not be judged by the ability to follow completely the broad division of categories in the individual and minute problems which arise in a large collection. The custodian of the photograph and slide collection will have need of all the clearsightedness and ingenuity that can be mustered, but there must ever be kept in mind the fundamental purpose of the collection, the use to which it will be put, and the public it serves. 